\title{
Clinical Trials that Utilize MRS as a Biomarker
}

\author{
Alexander Lin ${ }^{1}$, Ben Rowland ${ }^{1}$, and John R Griffiths ${ }^{2}$ \\ ${ }^{1}$ Center for Clinical Spectroscopy, Department of Radiology, Brigham and Women's Hospital, Harvard \\ Medical School, Boston, CA 02115 \\ ${ }^{2}$ Cancer Research UK Cambridge Institute, University of Cambridge, Li Ka Shing Centre, Robinson \\ Way, Cambridge CB2 ORE UK
}

\begin{abstract}
Magnetic resonance spectroscopy (MRS) is an ideal tool for therapeutic monitoring in clinical trials although its role has not been formally examined. An initial search for the use of MRS in a clinical trials database showed 488 studies; however many are ongoing and limited information is available about them. Therefore, the results were cross-referenced with the scientific literature to find those studies that have been completed and have produced peer-reviewed publications. This yielded 61 studies demonstrating that MRS is actively used in clinical trials. Its most frequent use is to study hepatic lipid content. This is followed by studies of skeletal muscle, using both proton and phosphorous MRS, and finally the brain, which surprisingly was the subject of only $15 \%$ of the total MRS studies found. A review and summary of these studies is provided to better understand how MRS is used in clinical trials, and to assess its importance as a non-invasive and quantitative biomarker for disease.
\end{abstract}

\section{Keywords:}

magnetic resonance spectroscopy, clinical trials, efficacy, evidence-based medicine, therapeutic monitoring, pharmaceutical intervention, intrahepatic triglyceride, ectopic lipid, muscle energetics, neurochemistry 


\section{INTRODUCTION}

The non-invasive and quantitative nature of magnetic resonance spectroscopy (MRS) makes it an excellent endpoint for use in clinical trials of drugs or other clinical interventions. In longitudinal studies, MRS can be performed repeatedly with no harmful consequence to the patient or the clinical target, unlike biopsy or other invasive measures. As a direct or surrogate biomarker, MRS is sensitive to the effects of medications that can be readily compared and correlated to other clinical measures. Since the publication of Evidence-Based Medicine (EBM) meta-analyses ${ }^{1}$, it is encouraging to see that MRS is being used in an increasing number of clinical trials. While some studies remain small, there are now many more clinical trials with significant cohort sizes that meet EBM criteria. The following is an overview of the use of MRS in recent clinical drug trials.

\subsection{Literature Search Criteria}

Since 2004, the International Committee of Medical Journal Editors (ICMJE) has required the registration of clinical trials as a condition of publication of research results. Also, in 2007 section 801 of the US Food and Drug Administration (FDA) has required by law that clinical trials of drugs be registered. The US National Institutes of Health (NIH)supported ClinicalTrials.gov website is a registry where all studies can provide the necessary information required by ICMJE and the FDA. This database is searchable and thus provides a valuable resource for mining data on the use of MRS in clinical trials. As many of the studies are still in progress, few have indicated finalized results within the ClinicalTrials.gov database. Furthermore as the results are not peer-reviewed, it is difficult to judge the quality of the studies from the limited information on the website. Fortunately, entries in the registry are tied to PubMed.gov, a citations database of published peer-reviewed literature. These two resources were used in combination to determine the extent of use of MRS by using "magnetic resonance spectroscopy" as a search term in ClinicalTrials.gov and then subsequently utilizing those results within PubMed by using the search terms: "clinicaltrials.gov[si]" and "magnetic resonance spectroscopy". The resulting list of publications was reviewed to eliminate those studies that did not utilize in vivo MRS (for example, the use of high resolution NMR or MRS for the characterization of blood and other 
body fluids, was eliminated). Individual studies were then further reviewed to include only prospective studies utilizing an intervention. For the purposes of this review, interventions included both pharmaceutical and non-pharmaceutical (i.e. diet changes or exercise changes) interventions. As a result, studies using MRS itself as an intervention, for example to determine if it provides better diagnosis, are excluded as they are described in another chapter [emrstm1474].

\subsection{Literature Search Results}

The initial search on ClinicalTrials.gov found 488 registered studies that utilize MRS as part of the study description or intervention. Of those studies, $318(65 \%)$ were interventional studies as opposed to observational studies. 195 of the studies focused specifically on a pharmaceutical drug intervention. This result demonstrates that there is substantial interesting in using MRS in clinical trials, particularly for the evaluation of treatment effects. The initial PubMed search, which included the ClinicalTrial.gov results, yielded 96 studies. Initial review of the study abstracts showed that 74 of those studies utilized in vivo MRS methods. Of those 74 studies, 61 focused on a specific intervention as opposed to a cross-sectional study. In almost all of these studies, the study design included controls with a placebo or equivalent existing medication.

The majority of the clinical drug trials focused on the use of MRS in the liver, specifically to measure hepatic lipid content in 25 studies (41\%). The second largest group of studies focused on studying skeletal muscle $(n=17,28 \%)$ using ${ }^{31} \mathrm{P}(\mathrm{n}=9)$ and ${ }^{1} \mathrm{H}$ MRS $(\mathrm{n}=$ 9, including one study used both ${ }^{31} \mathrm{P}$ and ${ }^{1} \mathrm{H}$ ) methods. The study counts of these two groups include four studies where both hepatic and skeletal muscle lipids were studied in the same patient. The next largest group of studies focused on the brain, with 15 studies (25\%) using multiple endpoints such as $\mathrm{N}$-acetylaspartate (NAA), cholines (Cho), glutamate (Glu), $\mathbf{p}$ aminobutyric acid (GABA), etc., and one study using ${ }^{31} \mathrm{P}$ MRS to measure brain energetics. Similarly both ${ }^{31} \mathrm{P}(\mathrm{n}=4)$ and ${ }^{1} \mathrm{H}$ MRS $(\mathrm{n}=3)$ were also used in seven cardiac interventional 
clinical trials representing $11.5 \%$ of the total studies. Finally, one study used MRS to monitor abdominal and pelvic tumors ${ }^{2}$. The mean number of subjects in each study was 37 , with a range of 7 to 154 subjects. 11 of the studies had 50 or more subjects and $65 \%$ of the studies showed significant differences and were therefore sufficiently powered.

\subsection{Use of Intrahepatic Triglyceride Content as a Drug Trial Endpoint}

Liver steatosis affects $20 \%$ of the population and is a key component of a number of major diseases including non-alcoholic fatty liver disease (NAFLD), the most common chronic liver disease, and hepatitis ${ }^{3}$. Intrahepatic triglyceride (IHTG) content is also involved with insulin resistance and may therefore play a role in obesity and diabetes ${ }^{4}$ (see also emrstm1470 and emrstm1436). While liver biopsy remains the gold standard for measuring hepatic steatosis and fibrosis, the invasive nature of the procedure means that it cannot be used repeatedly in humans to demonstrate metabolic improvement following drug administration. Other methods such as ultrasound and computed tomography (CT) do not provide accurate quantification of liver fat, and CT scans carry the additional burden of radiation exposure. In contrast, MRS can readily quantify $\mathrm{IHTG}^{5}$ without the need for biopsy or exposure to radiation. Perhaps for those reasons, the majority of clinical trials focusing upon liver steatosis have utilized IHTG as a clinical endpoint.

IHTG is measured using motion-corrected or breath-held single voxel acquisitions. Typically, additional frequency domain correction is applied, shifting each individual acquisition to align the water peaks before averaging them. Intensities of the hepatic water peaks $(4.7 \mathrm{ppm})$, and methylene peaks $\left(-\mathrm{CH}_{2}-\right)$ from the fatty acid chains $(1.3 \mathrm{ppm})$ are measured and corrected for spin-lattice $\left(\mathrm{T}_{1}\right)$ and spin-spin $\left(\mathrm{T}_{2}\right)$ relaxation, as shown in Figure 1 , and liver fat content is expressed as a ratio of the signal of the methylene group to the total signal of methylene plus water as percent fat by weight or volume ${ }^{6}$. This method has been widely accepted as the most accurate in vivo assessment of liver fat content (see also 
emrstm1470, 1478), and by consensus NAFLD is defined as liver fat $>5.6 \mathrm{mg}$ fat per $\mathrm{g}$ of liver tissue, or $5.6 \%(\mathrm{w} / \mathrm{w})$ of liver tissue weight ${ }^{6}$.

\section{$<$ Fig 1 near here>}

As would be expected, many of the drug trials that utilized IHTG as an endpoint focused on diseases such as NAFLD ${ }^{7-12}$. Several studies that examined the effect of pioglitazone, a thiazolidinedione that improves glucose and lipid metabolism, showed reductions in IHTG levels after drug administration ${ }^{7 ; 8 ; 10}$. Other studies focused on the use of mipomersen, an apolipoprotein synthesis inhibitor, in diseases such as hypercholesterolemia: these also showed reductions in hepatic lipid levels ${ }^{13 ; 14}$. Reduced IHTG or lack thereof has additionally been used to demonstrate the effectiveness of medications for insulin resistance ${ }^{8 ;}$ 15. Given IHTG's important role in obesity and diabetes, it is not surprising that there have also been many clinical trials that examined the effect of diet ${ }^{16-21}$, exercise ${ }^{22}$, and lifestyle changes ${ }^{23 ; 24}$ where IHTG was used as an outcome measure. One of the largest studies was a randomized controlled trial of 154 adults with NAFLD where 74 subjects underwent an intervention that included lifestyle modifications such as diet and exercise changes in conjunction with dietary and lifestyle consultations ${ }^{24}$. The primary outcome was remission of NAFLD after one year, as measured by reduction of IHTG levels to less than 5\%. The mean IHTG levels were reduced from $12.3 \%$ to $5.5 \%$ with successful resolution of NAFLD in $64 \%$ of the patients, which was significantly greater than in controls $(12.2 \%$ to $10.1 \%$ reduction and $20 \%$ resolution).

\subsection{Use of Muscle Spectroscopy as a Drug Trial Endpoint}

1.4.1. Skeletal Muscle Lipids. Similar to the use of IHCL, characterization of the lipid composition of skeletal muscle is also of special interest because of the direct relationship of body fat to obesity and its role in insulin resistance (see also emrstm1431). Intramyocellular triglyceride stores are utilized as a form of energy that decreases skeletal muscle glucose 
utilization, resulting in the impairment of glucose metabolism. Previous studies have shown increased intramyocellular lipid (IMCL) levels with obesity and diabetes ${ }^{25}$. While IMCL levels can be measured by biopsy or CT, these methods do not distinguish between intra- and extramyocellular (EMCL) lipid content, and of course they are also invasive or involve a radiation exposure.

Proton MRS, in contrast, can assess IMCL and EMCL levels non-invasively by measuring the resonances at 1.2 and $1.35 \mathrm{ppm}$, respectively. These peaks can be readily distinguished on an MRS spectrum ${ }^{26}$ as shown in Figure 2. Measurements of IMCL and EMCL are readily accomplished using conventional short spin-echo single voxel spectroscopy. However it is important that adipose tissue is excluded from the voxel volume and that the leg is positioned identically in each study, as EMCL signals are orientationdependent. Measurements of IMCL and IHTG are often used together to monitor lipid composition before and after treatments such as growth hormone therapy ${ }^{27}$ or dietary interventions ${ }^{25 ; 28 ; 29}$ where reductions of IMCL and IHTG are positive clinical endpoints. By themselves, IMCL endpoints have been utilized in studies examining the effect of medications such as simvastatin ${ }^{30}$ or creatine supplements ${ }^{31}$ which were shown to have little to no effect on IMCL levels. However, IMCL is certainly sensitive to the effect of exercise, since IMCL levels decrease after exercise ${ }^{32 ; 33}$. In some of the published studies IMCL levels did not change, demonstrating a lack of efficacy of the intervention.

$<$ Fig 2 near here >

1.4.2. Dynamic ${ }^{31} \mathbf{P}$ MRS of Skeletal Muscle. ${ }^{31} \mathrm{P}$ MRS is widely accepted as the "gold standard" method for noninvasive measurements of energy metabolism in exercising muscle ${ }^{34}$ (see also emrstm1442). During exercise, consumption of adenosine triphosphate (ATP) is almost stoichiometrically correlated to the net hydrolysis of phosphocreatine ( $\mathrm{PCr}$ ) to inorganic phosphate (Pi). Thus changes in PCr peak height measure the intracellular energy status, while the ppm difference between $\mathrm{Pi}$ and $\mathrm{PCr}$ directly measures intracellular $\mathrm{pH}$ in the 
same spectrum ${ }^{35 ; 36}$. The dynamics of Pi/PCr have been used to evaluate mitochondrial respiration in skeletal muscle ${ }^{37 ; 38}$, with the rate constant of post-exercise recovery kinetics of $[\mathrm{PCr}]$ serving as an index of mitochondrial function ${ }^{39-43}$.

Typically ${ }^{31} \mathrm{P}$ spectra are collected with a pulse-and-acquire sequence using a single loop surface coil placed near the muscle of interest. A magnetic resonance (MR)-compatible exercise device is used to perform an exercise within the MR scanner. Data are collected at rest, during exercise, and during the recovery phase. $\mathrm{PCr}$ is quantified for each time point and the time course during recovery is fitted with an exponential function to determine the rate constant, tau, which is representative of mitochondrial function. A higher tau value indicates a faster recovery and better mitochondrial function, and vice versa. Clinical trials that utilized ${ }^{31} \mathrm{P}$ MRS to evaluate the effect of interventions on muscle energetics have shown that growth hormone therapy (tesamorelin) ${ }^{44}$, SIRT1 gene activation (SRT2104) ${ }^{45}$, and ischemic preconditioning ${ }^{46}$ all improve $\mathrm{PCr}$ recovery rates and thus enhance mitochondrial function. On the other hand neoadjuvant chemotherapy reduces muscle energetics, as shown by reduced recovery rates ${ }^{47}$. Other studies have shown no effect on muscle metabolism by creatine supplements ${ }^{48 ; 49}$, statin medications (simvastatin) ${ }^{50}$, and Vitamin D (cholecalciferol) therapies ${ }^{51}$.

1.4.3. Cardiac Spectroscopy. Similar to the methods employed in skeletal muscle, cardiac muscle has also been assessed by ${ }^{1} \mathrm{H}$ and ${ }^{31} \mathrm{P}$ spectroscopy yielding similar biomarkers of myocardial triglyceride content and energetics (see emrstm1453,1488). However, in ${ }^{31} \mathrm{P}$ MRS, the PCr/ATP ratio is used instead of the post exercise PCr recovery used in skeletal muscle. Spectroscopy in the heart is made much more challenging by its rapid movement in addition to breathing motion, thus requiring more sophisticated pulse sequences for prospective motion correction for ${ }^{1} \mathrm{H}$ MRS and for volume localization with ${ }^{31} \mathrm{P}$ MRS.

Nonetheless, ${ }^{1} \mathrm{H}$ MRS cardiac studies have shown that myocardial lipid levels rise when subjects have free fatty acid levels increased by hyperinsulinemic-euglycemic clamping 
and intralipid infusion ${ }^{52}$. It is therefore not surprising that a fat-reduced diet would result in lower myocardial triglyceride levels ${ }^{53}$ although insulin sensitization by thiazolidinedione medication (rosiglitazone) does not have an effect ${ }^{54}$. Cardiac energetics can be improved in patients with heart failure using intravenous Allopurinol, a xanthine oxidase inhibitor which affects ATP synthesis ${ }^{55}$. Similarly perhexiline, which shifts myocardial metabolism from fatty acid to glucose utilization, improves cardiac energetics and exercise capacity in patients with hypertrophic cardiomyopathy or thickening of cardiac muscles ${ }^{56}$. Low dose hormone therapy, however, does not appear to improve muscle energetics in women who have myocardial ischemia ${ }^{57}$.

\subsection{Use of Neuro-spectroscopy as a Drug Trial Endpoint}

Unlike MRS in the liver or muscle which provides only one or two measures, ${ }^{1} \mathrm{H}$ MRS of the brain is rich with a large number of different endpoints that can be used for clinical trials. The most studied are: NAA which can be used to monitor neuronal health; Cho which indicates membrane turnover and can be used to assess tissue damage due to brain injury or cancer; measures of total (PCr plus unphosphorylated) creatine, $\mathrm{Cr}$, which can be used as an energy marker although in most cases it serves as an internal reference; myo-inositol (mI) is an osmolyte and astrocytic marker; Glu (which is often indistinguishable from glutamine, they are frequently quantified jointly as Glx) is an excitatory neurotransmitter that is often modulated by disease and treatment; GABA is an inhibitory neurotransmitter; and finally

glutathione $(\mathrm{GSH})$ is an anti-oxidant whose levels may reflect neuro-inflammation ${ }^{58}$. Given the many different biological roles of these metabolites, there is an equally broad range of neurological diseases that can affect them.

Starting first with brain cancer (see the description of the eTUMOR and INTERPRET trials in emrstm1474), MRS can also be utilized for therapeutic monitoring to determine the efficacy of medications. Anti-angiogenic medications such as bevacizumab inhibit the VEGF pathway, resulting in reduced formation of tumor neovasculature. Ratai et al examined 
thirteen patients with recurrent histologically-proven glioblastoma multiforme that had failed to respond to radiotherapy, before and after administration of bevacizumab in addition to the conventional treatment regimen ${ }^{59}$. NAA/Cho levels increased and Cho/Cr levels decreased two weeks after treatment, a change that correlated with progression-free survival 6 months to a year later. It is important to note that this study spanned three different sites with three different scanners yet was able to provide consistent results. This is largely the benefit of a pre-post treatment study design wherein the subject serves as their own control, thus providing greater statistical power and eliminating the effects of inter-subject and interinstitutional variations.

The largest clinical trial that used MRS of the brain for testing drug efficacy was a randomized controlled clinical trial comparing memantine, an N-methyl-D-aspartate agonist with possible neuroprotective effects in Alzheimer's disease (AD), with donepezil, a cholinesterase inhibitor that is the prevailing medication used for treating $\mathrm{AD}^{60}$. 63 subjects were examined before and 6 months after treatment. It was anticipated that decreased NAA and increased $\mathrm{mI}$ found in $\mathrm{AD}$ may be reversed or levels preserved following medication but both medications showed worsening of NAA levels rather than improvement. The NAA levels correlated significantly with neurocognitive assessments, demonstrating that both methods accurately reflected the failures of the two medications. In a smaller study ( $n=17)$ of subjects with mild cognitive impairment, a transitional stage to dementia, MRS was used to assess treatment with growth-hormone releasing hormone ${ }^{61}$. MRS was obtained at baseline, 10 weeks, and 20 weeks into the treatment. Their results demonstrated increased Nacetylaspartylglutamate (NAAG) levels and decreased mI levels, indicative of a favorable treatment effect. In addition, they observed increased GABA levels. The next largest study also focused on cognitive impairment, induced in that case by human immunodeficiency virus. A total of 62 patients were enrolled in a randomized placebo-controlled trial evaluating the benefits of the selegiline transdermal system which is thought to have anti-oxidant effects 
62. Similar to the study in $\mathrm{AD}$, the treatment did not appear to have an effect on the brain metabolites, which was also reflected in a lack of effect on cognitive function.

Multiple sclerosis (MS) is an inflammatory disease that results in demyelination of white matter axonal tracts. Filippi et al studied the effects of the immunotherapeutic laquinimod in a phase III study of 27 relapsing-remitting MS patients, of whom 12 received laquinimod and the others a placebo. While the MRS results were not significantly different, there appeared to be a trend towards increased NAA. Unfortunately the researchers had utilized a long spin-echo acquisition, which did not allow the study of other biomarkers such as GSH. GSH however was the focus of a study on therapy with N-acetylcysteine, a metabolic pre-cursor of GSH: administration resulted in increased GSH levels in 6 subjects (3 with Parkinson's disease and 3 with Gaucher's disease, both of which involve oxidative stress) when compared to 3 controls. This preliminary result shows that MRS is a promising tool for monitoring neuroinflammation.

As systemic changes can also affect brain metabolism, MRS of the brain has been used for assessing the effect of treatments for diseases that originate outside of the brain. Hepatic encephalopathy results from liver diseases that affect the brain via circulating toxins, such as ammonia, resulting in increased Glx and reduced mI, Cho, and eventually NAA. A study of 60 subjects with minimal hepatic encephalopathy examined the effect of lactulose, which reduces levels of ammonia in the body. MRS conducted before and after 3 months of treatment demonstrated a positive outcome, as measured by MRS, with increases in $\mathrm{mI}$ and Cho and reductions in Glx. Another study examined the effects of post-cancer fatigue in 39 subjects treated with cognitive behavioral therapy: however in this case there was no effect of the treatment ${ }^{63}$. In contrast, another smaller clinical trial utilizing cognitive behavioral therapy to reduce pain in fibromyalgia, a syndrome with similar symptoms to cancer fatigue, did show changes (reduced Glu/Cr in 10 subjects) ${ }^{64}$.

Psychiatric disorders have also utilized MRS heavily for the evaluation of drug efficacy. In the majority of the studies, glutamate levels appear to be the most important 
indicators of response. For example, acamprosate has been successfully used to treat alcoholism although its mechanism of action is unclear. It is thought that it may act through regulation of a hyper-glutamatergic state resulting from cyclic intoxication and withdrawal. In one study, 33 patients undergoing alcohol withdrawal were given acamprosate or placebo and MRS was acquired before and after treatment ${ }^{65}$. There were significant reductions of brain glutamate, in those subjects given acamprosate when compared to the placebo group, thus supporting the hypothesis. Similarly, ten adolescents suffering from attention deficit hyperactivity disorder, which also results in excess intracerebral glutamate, were given the stimulant methylphenidate, to determine if Glu would change ${ }^{66}$. Although significant differences between control and ADHD subjects were observed, the medication itself did not appear to alter cerebral Glu levels. Using a more cognitive approach, and relying on measures of NAA and Cho rather than Glu, another study examined 8 bipolar patients before and after administration of galantamine, an acetylcholinesterase inhibitor, and found an increase in NAA and decrease in Cho, thus demonstrating changes indicative of restoration of cognition ${ }^{67}$. The same group utilized ${ }^{31} \mathrm{P}$ MRS and found that patients $(\mathrm{n}=6)$ with major depressive disorder who responded to triiodothyronine, a thyroid hormone with antidepressant effects, showed significantly increased brain ATP levels compared to nonresponders $(n=10)^{68}$.

Given the relative ease of acquiring spectra from the brain (with typically no need for motion correction, for example), it is somewhat surprising that there have been fewer clinical trials using MRS in the brain than in the liver and muscle. Issues such as reproducibility and differences in protocols, as described earlier in this chapter, certainly play a role; however one of the main differences is that unlike liver and muscle spectroscopy, where the measures are direct assessments of lipid or energetics, neuro-spectroscopy metabolites such as NAA are putative and indirect markers of brain health. The more recent studies that focused on neurotransmitters such as Glu and GABA are perhaps utilizing more direct measure of cerebral metabolism, although even here, arguably, the metabolite measurements represent 
steady-state concentrations of pools of the neurotransmitters and do not take into account the dynamic exchange of these metabolites. The advent of advanced MRS methods such as ${ }^{13} \mathrm{C}$ labelled spectroscopy and hyperpolarized MRS may help to overcome some of these barriers.

\section{BIOGRAPHICAL SKETCHES}

Alexander Lin, $\mathrm{PhD}$, obtained his degree in Biochemistry and Molecular Biophysics and is currently the director of the Center for Clinical Spectroscopy at Brigham and Women's hospital and Harvard Medical School. He has been actively pursuing clinical applications of MRS since 1997 including recent work in clinical trials.

Ben Rowland, DPhil (Oxon), is the MR physicist for the Center for Clinical Spectroscopy. The focus of his research in MRS has been the development of MRS algorithms and software packages that improve and enhance MRS in clinical practice.

John Griffiths MB BS, D Phil, FRCP, qualified in medicine and biochemistry. In the early 1980s, his research group pioneered the use of MRS for studies on living tumors, and he has worked since then on MRI and MRS of cancer, both in vivo and ex vivo. He has published more than 300 peer-reviewed articles to date. His recent interests include the metabolomics of cancer. 


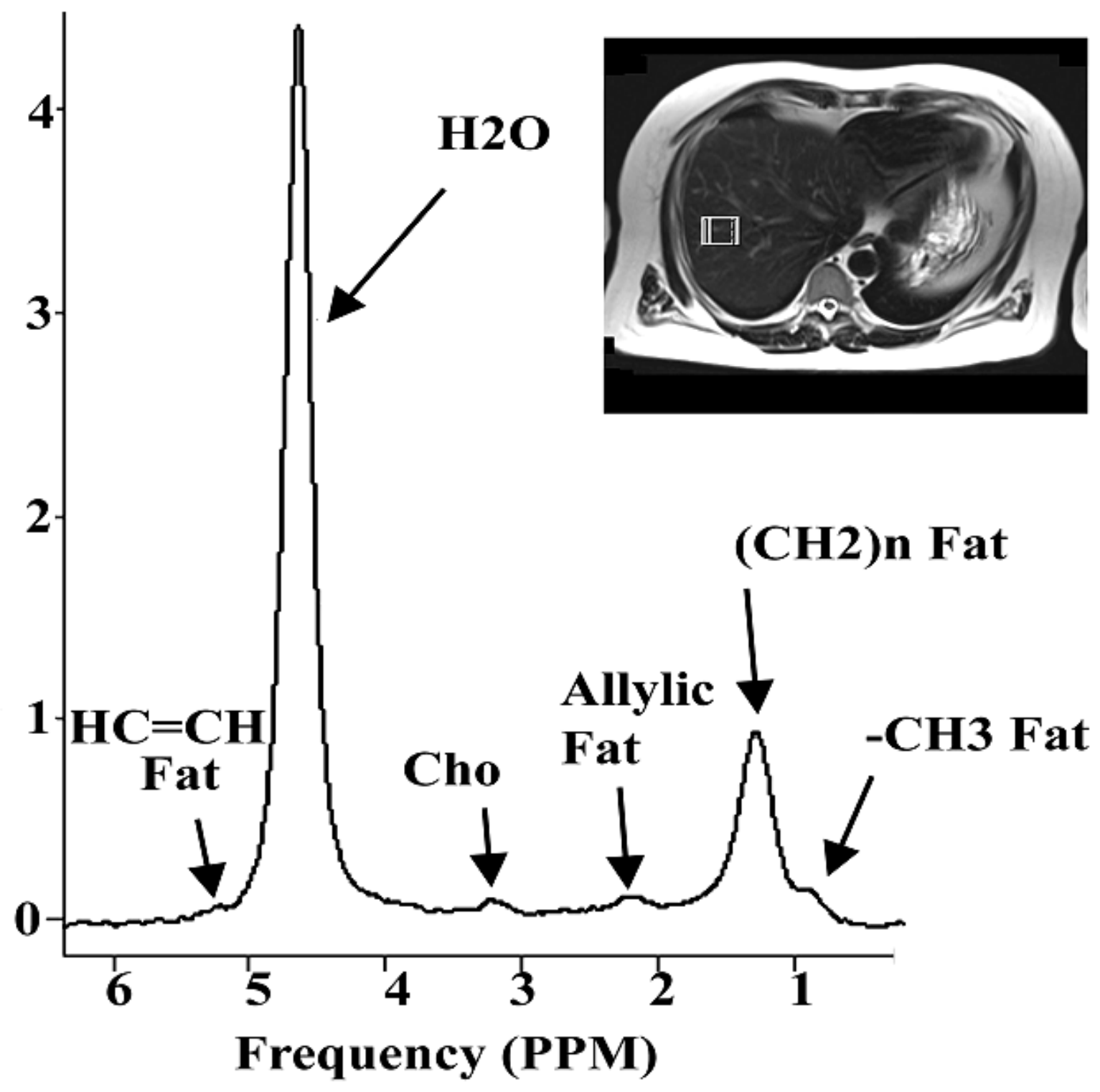

Figure 1. Measuring Lipid Content in the Liver using ${ }^{1} \mathrm{H}$ MRS. The spectrum was acquired from the right lobe of the liver in a healthy volunteer using breath-held single voxel spectroscopy (PRESS, echo-time $\mathrm{TE}=35 \mathrm{~ms}, 16$ averages) on at 3T MR scanner (Siemens Verio) using an 8 channel phased array torso surface coil. 

A. Lidodystrophy
B. Control
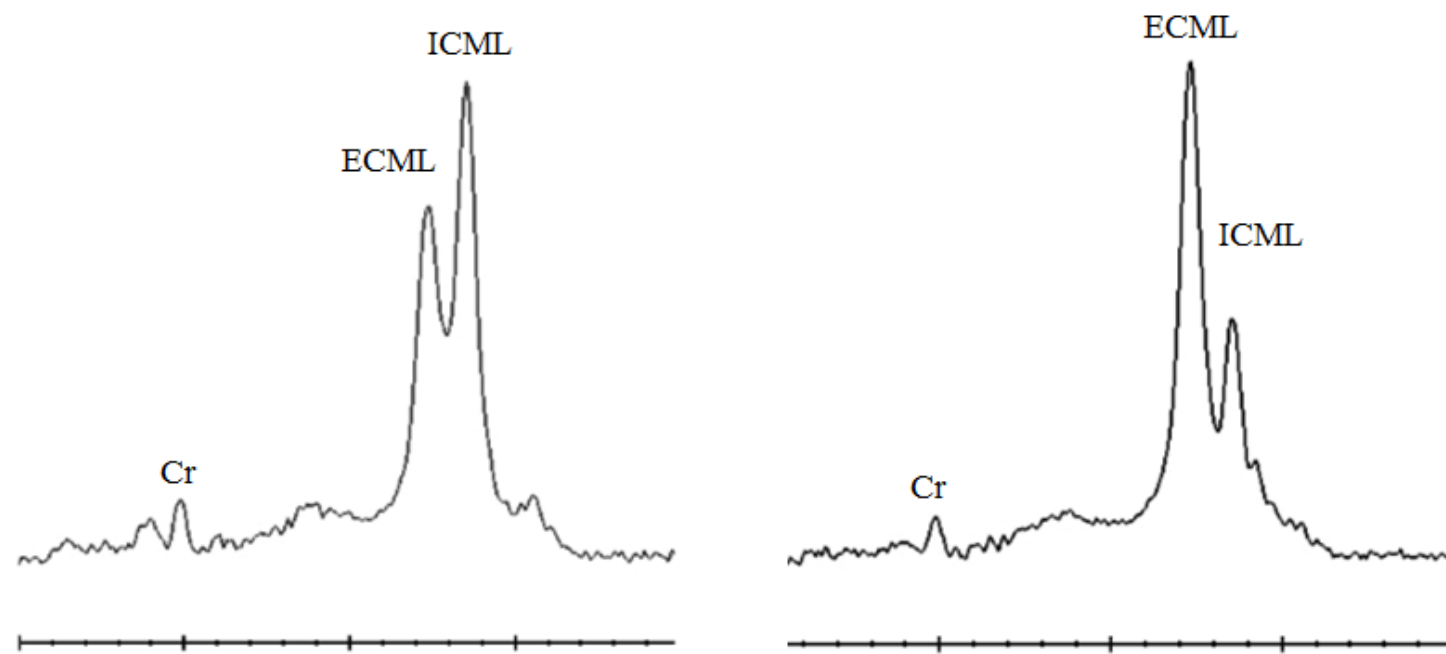

Figure 2. Measuring Intramyocellular Lipid in Skeletal Muscle using ${ }^{1}$ H MRS. Single voxel spectra were acquired from the skeletal muscle of (a) a human immuno-deficiency virus (HIV)-positive patient suffering from lipodystrophy as compared to b) control with no lipodystrophy using a lower extremity transmit-receive coil at $1.5 \mathrm{~T}$ (using a GE Signa scanner) ${ }^{69}$. Note the increase in extramyocellular lipid (EMCL) when compared the intramyocellular lipids (IMCL). 


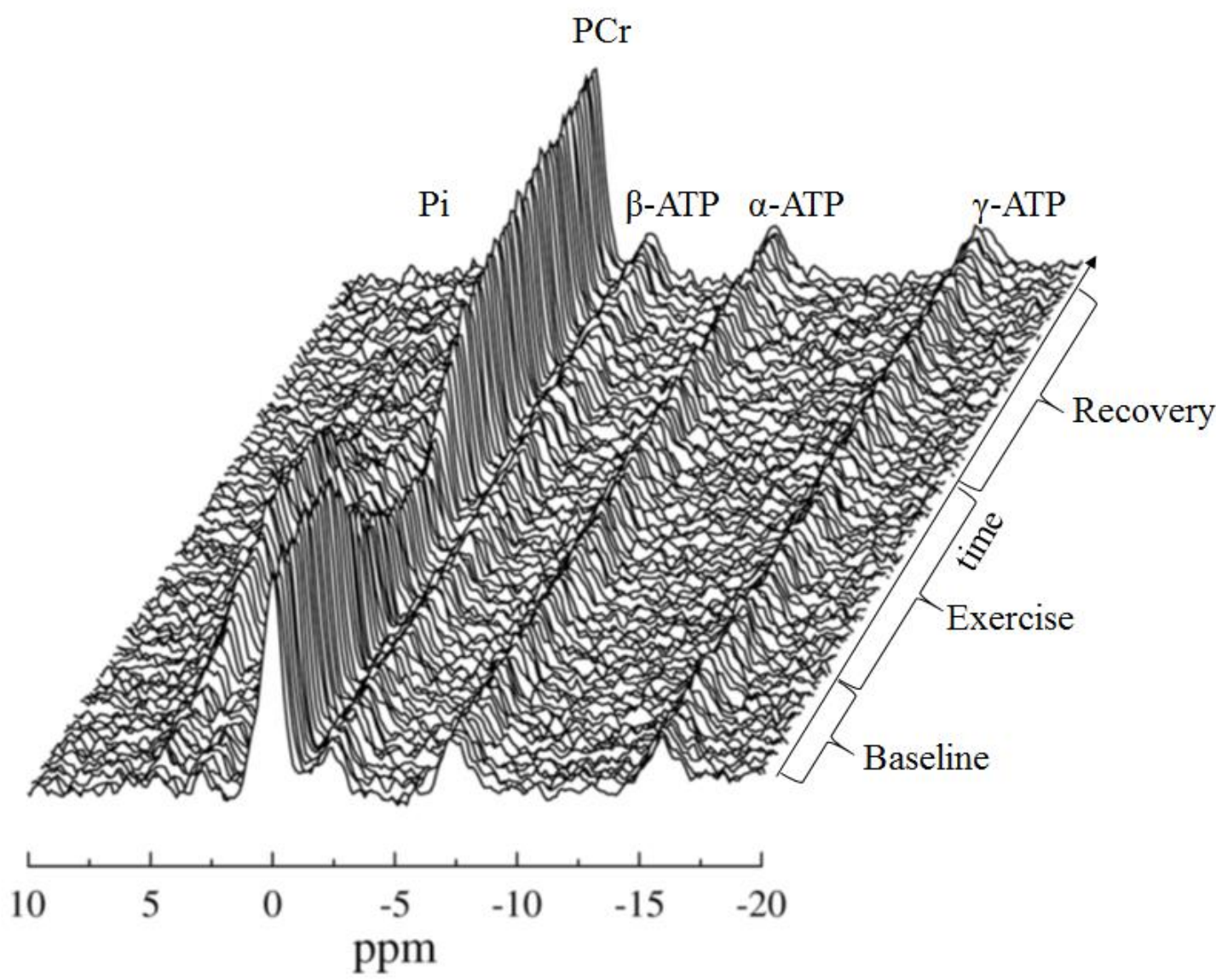

Figure 3. Dynamic ${ }^{31} \mathrm{P}$ MRS of Skeletal Muscle. A stackplot of spectra acquired during baseline, exercise, and recovery (annotated at right) is shown. Spectra were acquired using a non-localized $90^{\circ}$ pulse-and-acquire sequence (repetition period $T R=2$ secs, spectral width of $6 \mathrm{kHz}$ ) using a single channel ${ }^{31} \mathrm{P}$ coil at $3 \mathrm{~T}$ (Siemens Verio) from $\mathrm{B}$. Rowland et al. $2015^{70}$ Reproduced bv permission of Wiley Periodicals, Inc. 


\section{References}

1. A. P. Lin, T. T. Tran and B. D. Ross, NMR Biomed, 2006, 19, 476.

2. T. A. Yap, L. Yan, A. Patnaik, N. Tunariu, A. Biondo, I. Fearen, K. P. Papadopoulos, D. Olmos, R. Baird, L. Delgado, E. Tetteh, R. A. Beckman, L. Lupinacci, R. Riisnaes, S. Decordova, S. P. Heaton, K. Swales, N. M. deSouza, M. O. Leach, M. D. Garrett, D. M. Sullivan, J. S. de Bono and A. W. Tolcher, Clin Cancer Res, 2014, 20, 5672.

3. K. L. Milner, D. van der Poorten, M. Trenell, A. B. Jenkins, A. Xu, G. Smythe, G. J. Dore, A. Zekry, M. Weltman, V. Fragomeli, J. George and D. J. Chisholm, Gastroenterology, 2010, 138, 932.

4. R. C. Mollard, M. Senechal, A. C. MacIntosh, J. Hay, B. A. Wicklow, K. D. Wittmeier, E. A. Sellers, H. J. Dean, L. Ryner, L. Berard and J. M. McGavock, Am J Clin Nutr, 2014, 99, 804.

5. S. B. Reeder, I. Cruite, G. Hamilton and C. B. Sirlin, J Magn Reson Imaging, 2011, $34,729$.

6. L. S. Szczepaniak, P. Nurenberg, D. Leonard, J. D. Browning, J. S. Reingold, S. Grundy, H. H. Hobbs and R. L. Dobbins, Am J Physiol Endocrinol Metab, 2005, 288, E462.

7. R. Belfort, S. A. Harrison, K. Brown, C. Darland, J. Finch, J. Hardies, B. Balas, A. Gastaldelli, F. Tio, J. Pulcini, R. Berria, J. Z. Ma, S. Dwivedi, R. Havranek, C. Fincke, R. DeFronzo, G. A.

Bannayan, S. Schenker and K. Cusi, N Engl J Med, 2006, 355, 2297.

8. E. Phielix, A. Brehm, E. Bernroider, M. Krssak, C. H. Anderwald, M. Krebs, A. I. Schmid, P. Nowotny and M. Roden, Diabetes Obes Metab, 2013, 15, 915.

9. R. Safadi, F. M. Konikoff, M. Mahamid, S. Zelber-Sagi, M. Halpern, T. Gilat and R. Oren, Clin Gastroenterol Hepatol, 2014, 12, 2085.

10. S. L. Samson, P. Sathyanarayana, M. Jogi, E. V. Gonzalez, A. Gutierrez, R. Krishnamurthy, R. Muthupillai, L. Chan and M. Bajaj, Diabetologia, 2011, 54, 3093.

11. E. Scorletti, L. Bhatia, K. G. McCormick, G. F. Clough, K. Nash, P. C. Calder and C. D. Byrne, Contemp Clin Trials, 2014, 37, 301.

12. N. Stefan, M. Ramsauer, P. Jordan, B. Nowotny, K. Kantartzis, J. Machann, J. H. Hwang, P. Nowotny, S. Kahl, J. Harreiter, S. Hornemann, A. J. Sanyal, P. M. Stewart, A. F. Pfeiffer, A. Kautzky-Willer, M. Roden, H. U. Haring and S. Furst-Recktenwald, Lancet Diabetes Endocrinol, 2014, 2, 406.

13. M. E. Visser, F. Akdim, D. L. Tribble, A. J. Nederveen, T. J. Kwoh, J. J. Kastelein, M. D. Trip and E. S. Stroes, J Lipid Res, 2010, 51, 1057.

14. M. E. Visser, G. Wagener, B. F. Baker, R. S. Geary, J. M. Donovan, U. H. Beuers, A. J.

Nederveen, J. Verheij, M. D. Trip, D. C. Basart, J. J. Kastelein and E. S. Stroes, Eur Heart J, 2012, 33, 1142.

15. F. van der Valk, C. Hassing, M. Visser, P. Thakkar, A. Mohanan, K. Pathak, C. Dutt, V. Chauthaiwale, M. Ackermans, A. Nederveen, M. Serlie, M. Nieuwdorp and E. Stroes, PLoS One, 2014, 9, e86890.

16. M. Bortolotti, R. Kreis, C. Debard, B. Cariou, D. Faeh, M. Chetiveaux, M. Ith, P. Vermathen, N. Stefanoni, K. A. Le, P. Schneiter, M. Krempf, H. Vidal, C. Boesch and L. Tappy, Am J Clin Nutr, 2009, 90, 1002.

17. J. D. Browning, J. A. Baker, T. Rogers, J. Davis, S. Satapati and S. C. Burgess, Am J Clin Nutr, 2011, 93, 1048.

18. R. D. Johnston, M. C. Stephenson, H. Crossland, S. M. Cordon, E. Palcidi, E. F. Cox, M. A. Taylor, G. P. Aithal and I. A. Macdonald, Gastroenterology, 2013, 145, 1016.

19. H. Kahleova, L. Belinova, H. Malinska, O. Oliyarnyk, J. Trnovska, V. Skop, L. Kazdova, M. Dezortova, M. Hajek, A. Tura, M. Hill and T. Pelikanova, Diabetologia, 2014, 57, 1552.

20. K. E. Koopman, M. W. Caan, A. J. Nederveen, A. Pels, M. T. Ackermans, E. Fliers, S. E. la Fleur and M. J. Serlie, Hepatology, 2014, 60, 545.

21. M. Ramon-Krauel, S. L. Salsberg, C. B. Ebbeling, S. D. Voss, R. V. Mulkern, M. M. Apura, E. A. Cooke, K. Sarao, M. M. Jonas and D. S. Ludwig, Child Obes, 2013, 9, 252.

22. S. Sullivan, E. P. Kirk, B. Mittendorfer, B. W. Patterson and S. Klein, Hepatology, 2012, 55, 1738.

23. J. Shen, G. L. Wong, H. L. Chan, R. S. Chan, H. Y. Chan, W. C. Chu, B. H. Cheung, D. K. Yeung, L. S. Li, M. M. Sea, J. Woo and V. W. Wong, J Gastroenterol Hepatol, 2015, 30, 139. 24. V. W. Wong, R. S. Chan, G. L. Wong, B. H. Cheung, W. C. Chu, D. K. Yeung, A. M. Chim, J. W. Lai, L. S. Li, M. M. Sea, F. K. Chan, J. J. Sung, J. Woo and H. L. Chan, J Hepatol, 2013, 59, 536. 25. K. A. Le, M. Ith, R. Kreis, D. Faeh, M. Bortolotti, C. Tran, C. Boesch and L. Tappy, Am J Clin Nutr, 2009, 89, 1760.

26. C. Boesch and R. Kreis, Ann NY Acad Sci, 2000, 904, 25.

27. K. C. Yuen, C. T. Roberts, Jr., J. Frystyk, W. D. Rooney, J. R. Pollaro, B. J. Klopfenstein and J. Q. Purnell, J Clin Endocrinol Metab, 2014, 99, E1862. 
28. M. Maersk, A. Belza, H. Stodkilde-Jorgensen, S. Ringgaard, E. Chabanova, H. Thomsen, S. B. Pedersen, A. Astrup and B. Richelsen, Am J Clin Nutr, 2012, 95, 283.

29. L. E. Mayer, D. A. Klein, E. Black, E. Attia, W. Shen, X. Mao, D. C. Shungu, M. Punyanita, D. Gallagher, J. Wang, S. B. Heymsfield, J. Hirsch, H. N. Ginsberg and B. T. Walsh, Am J Clin Nutr, 2009, 90, 1132.

30. J. Szendroedi, C. Anderwald, M. Krssak, M. Bayerle-Eder, H. Esterbauer, G. Pfeiler, A. Brehm, P. Nowotny, A. Hofer, W. Waldhausl and M. Roden, Diabetes Care, 2009, 32, 209.

31. B. Gualano, R. Lugaresi, V. de Salles Painelli, A. C. Queiroz, G. Artioli, H. Roschel, M. C. Otaduy, C. Leite Cda and A. H. Lancha, Jr., Appl Physiol Nutr Metab, 2011, 36, 764.

32. A. Egger, R. Kreis, S. Allemann, C. Stettler, P. Diem, T. Buehler, C. Boesch and E. R. Christ, PLoS One, 2013, 8, e70865.

33. S. Jenni, C. Oetliker, S. Allemann, M. Ith, L. Tappy, S. Wuerth, A. Egger, C. Boesch, P. Schneiter, P. Diem, E. Christ and C. Stettler, Diabetologia, 2008, 51, 1457.

34. Layec G, Bringard A, Le Fur Y, Vilmen C, Micallef JP, Perrey S, Cozzone PJ, Bendahan D. , Magn Reson Med. 62(4):840-54. PubMed PMID: 19725136., 2009.

35. Chance B, Im J, Nioka S, Kushmerick M. , NMR Biomed. 19(7):904-26. Review. PubMed PMID: 17075955., 2006.

36. Prompers JJ, Jeneson JA, Drost MR, Oomens CC, Strijkers GJ, Nicolay K. , NMR Biomed. 19(7):927-53. Review. PubMed PMID: 17075956., 2006.

37. K. J. Forbes SC, Thompson RT, Marsh GD. , J Appl Physiol. 102:1565-1573., 2007.

38. Forbes SC, Slade JM, Meyer RA. , Appl Physiol Nutr Metab. 33(6):1124-31. PubMed PMID: 19088770., 2008.

39. Arnold DL, Matthews PM, Radda GK. , Magn Reson Med. 1:307-315., 1984.

40. McCully KK, Fielding RA, Evans WJ, Leigh JS Jr, Posner JD. , J Appl Physiol. 75:813-819., 1993.

41. Roussel M, Bendahan D, Mattei JP, Le Fur Y, Cozzone PJ. , Biochim Biophys Acta. 1457:1826., 2000.

42. Bendahan D, Desnuelle C, Vanuxem D, Confort-Gouny S, Figarella- Branger D, Pellissier JF, Kozak-Ribbens G, Pouget J, Serratrice G, Cozzone PJ. , Neurology, 42:1203-1208., 1992.

43. G. H. Raymer GH, Ranney DA, Marsh GD, Thompson RT. , J Appl Physiol. 106(4):1198-206. Epub 2008 Dec 26. PubMed PMID: 19112160., 2009.

44. H. Makimura, C. A. Murphy, M. N. Feldpausch and S. K. Grinspoon, J Clin Endocrinol Metab, 2014, 99, 338.

45. V. Libri, A. P. Brown, G. Gambarota, J. Haddad, G. S. Shields, H. Dawes, D. J. Pinato, E. Hoffman, P. J. Elliot, G. P. Vlasuk, E. Jacobson, M. R. Wilkins and P. M. Matthews, PLoS One, 2012, 7, e51395.

46. M. Andreas, A. I. Schmid, M. Keilani, D. Doberer, J. Bartko, R. Crevenna, E. Moser and M. Wolzt, J Cardiovasc Magn Reson, 2011, 13, 32.

47. M. A. West, L. Loughney, D. Lythgoe, C. P. Barben, V. L. Adams, W. E. Bimson, M. P. Grocott, S. Jack and G. J. Kemp, PLoS One, 2014, 9, e111526.

48. A. P. Hayashi, M. Y. Solis, M. T. Sapienza, M. C. Otaduy, A. L. de Sa Pinto, C. A. Silva, A. M. Sallum, R. M. Pereira and B. Gualano, Lupus, 2014, 23, 1500.

49. G. K. Sakkas, K. Mulligan, M. Dasilva, J. W. Doyle, H. Khatami, T. Schleich, J. A. Kent-Braun and M. Schambelan, PLoS One, 2009, 4, e4605.

50. A. M. West, J. D. Anderson, F. H. Epstein, C. H. Meyer, H. Wang, K. D. Hagspiel, S. S. Berr, N. L. Harthun, A. L. Weltman, J. M. Dimaria, J. R. Hunter, J. M. Christopher and C. M. Kramer, J Am Coll Cardiol, 2011, 58, 1068.

51. R. Gupta, U. Sharma, N. Gupta, M. Kalaivani, U. Singh, R. Guleria, N. R. Jagannathan and R. Goswami, Clin Endocrinol (Oxf), 2010, 73, 445.

52. R. Nielsen, H. Norrelund, U. Kampmann, W. Y. Kim, S. Ringgaard, M. Schar, N. Moller, H. E. Botker and H. Wiggers, Circ Heart Fail, 2013, 6, 845.

53. W. Utz, S. Engeli, S. Haufe, P. Kast, J. Bohnke, V. Haas, M. Hermsdorf, S. Wiesner, M. Pofahl, J. Traber, F. C. Luft, M. Boschmann, J. Jordan and J. Schulz-Menger, Int J Cardiol, 2013, 167, 905.

54. J. McGavock, L. S. Szczepaniak, C. R. Ayers, S. M. Abdullah, R. See, M. O. Gore, M. H. Drazner, J. A. de Lemos and D. K. McGuire, Diab Vasc Dis Res, 2012, 9, 131.

55. G. A. Hirsch, P. A. Bottomley, G. Gerstenblith and R. G. Weiss, J Am Coll Cardiol, 2012, 59, 802.

56. K. Abozguia, P. Elliott, W. McKenna, T. T. Phan, G. Nallur-Shivu, I. Ahmed, A. R. Maher, K. Kaur, J. Taylor, A. Henning, H. Ashrafian, H. Watkins and M. Frenneaux, Circulation, 2010, 122, 1562. 
57. C. N. Merz, M. B. Olson, C. McClure, Y. C. Yang, J. Symons, G. Sopko, S. F. Kelsey, E. Handberg, B. D. Johnson, R. M. Cooper-DeHoff, B. Sharaf, W. J. Rogers and C. J. Pepine, Am Heart J, 2010, 159, 987.e1.

58. A. Lin, B. D. Ross, K. Harris and W. Wong, NeuroRx, 2005, 2, 197.

59. E. M. Ratai, Z. Zhang, B. S. Snyder, J. L. Boxerman, Y. Safriel, R. C. McKinstry, F. Bokstein, M. R. Gilbert, A. G. Sorensen and D. P. Barboriak, Neuro Oncol, 2013, 15, 936.

60. P. J. Modrego, N. Fayed, J. M. Errea, C. Rios, M. A. Pina and M. Sarasa, Eur J Neurol, 2010, $17,405$.

61. S. D. Friedman, L. D. Baker, S. Borson, J. E. Jensen, S. M. Barsness, S. Craft, G. R. Merriam, R. K. Otto, E. J. Novotny and M. V. Vitiello, JAMA Neurol, 2013, 70, 883.

62. G. Schifitto, C. T. Yiannoutsos, T. Ernst, B. A. Navia, A. Nath, N. Sacktor, C. Anderson, C. M. Marra and D. B. Clifford, Neurology, 2009, 73, 1975.

63. H. Prinsen, A. Heerschap, G. Bleijenberg, M. J. Zwarts, J. W. Leer, J. J. van Asten, M. van der Graaf, M. Rijpkema and H. W. van Laarhoven, PLoS One, 2013, 8, e74638.

64. R. E. Harris, P. C. Sundgren, Y. Pang, M. Hsu, M. Petrou, S. H. Kim, S. A. McLean, R. H. Gracely and D. J. Clauw, Arthritis Rheum, 2008, 58, 903.

65. J. C. Umhau, R. Momenan, M. L. Schwandt, E. Singley, M. Lifshitz, L. Doty, L. J. Adams, V. Vengeliene, R. Spanagel, Y. Zhang, J. Shen, D. T. George, D. Hommer and M. Heilig, Arch Gen Psychiatry, 2010, 67, 1069.

66. P. Hammerness, J. Biederman, C. Petty, A. Henin and C. M. Moore, CNS Neurosci Ther, 2012, 18,34

67. D. V. Iosifescu, C. M. Moore, T. Deckersbach, C. A. Tilley, M. J. Ostacher, G. S. Sachs and A. A. Nierenberg, CNS Neurosci Ther, 2009, 15, 309.

68. D. V. Iosifescu, N. R. Bolo, A. A. Nierenberg, J. E. Jensen, M. Fava and P. F. Renshaw, Biol Psychiatry, 2008, 63, 1127.

69. A. Lin, J. Denham, J. Smillie, A. Wijesinge, C. Enriquez, K. Harris, K. Shriner and B. D. Ross, ISMRM Workshop on Dynamic Spectroscopy and Measurements of Physiology, 2003.

70. B. Rowland, S. K. Merugumala, H. Liao, M. A. Creager, J. Balschi and A. P. Lin, Magn Reson Med, 2015. 